\title{
Characterisation of glyoxalase $I$ in a streptozocin-induced mouse model of diabetes with painful and insensate neuropathy
}

\author{
M. M. Jack • J. M. Ryals • D. E. Wright
}

Received: 8 November 2010 / Accepted: 27 April 2011 /Published online: 3 June 2011

(C) Springer-Verlag 2011

\begin{abstract}
Aims/hypothesis Diabetic peripheral neuropathy (DN) is a common complication of diabetes; however, the mechanisms producing positive or negative symptoms are not well understood. The enzyme glyoxalase I (GLO1) detoxifies reactive dicarbonyls that form AGEs and may affect the way sensory neurons respond to heightened AGE levels in DN. We hypothesised that differential GLO1 levels in sensory neurons may lead to differences in AGE formation and modulate the phenotype of DN.

Methods Inbred strains of mice were used to assess the variability of Glo1 expression by quantitative RT-PCR. Non-diabetic C57BL/6 mice were used to characterise the distribution of GLO1 in neural tissues by immunofluorescence. Behavioural assessments were conducted in diabetic $\mathrm{A} / \mathrm{J}$ and $\mathrm{C} 57 \mathrm{BL} / 6$ mice to determine mechanical sensitivity, and GLO1 abundance was determined by western blot.

Results GLO1immunoreactivity was found throughout the nervous system, but selectively in small, unmyelinated peptidergic dorsal root ganglia (DRG) neurons that are involved in pain transmission. GLO1 protein was present at various levels in DRG from different inbred mice strains. Diabetic A/J and C57BL/6 mice, two mouse strains with different levels of GLO1, displayed dramatically different behavioural responses to mechanical stimuli. Diabetic C57BL/6 mice also had a reduced abundance of GLO1 following diabetes induction.
\end{abstract}

Electronic supplementary material The online version of this article (doi:10.1007/s00125-011-2196-3) contains supplementary material, which is available to authorised users.

M. M. Jack · J. M. Ryals $\cdot$ D. E. Wright $(\bowtie)$

Department of Anatomy and Cell Biology,

University of Kansas Medical Center,

Kansas City, KS 66160, USA

e-mail: dwright@kumc.edu
Conclusions/interpretation These findings reveal that the abundance of GLO1 varies between different murine strains and within different sensory neuron populations. These differences could lead to different responses of sensory neurons to the toxic effects of hyperglycaemia and reactive dicarbonyls associated with diabetes.

Keywords Advanced glycation end-products - Allodynia . Diabetic neuropathy · Dorsal root ganglia - Glyoxalase I . Mechanical sensitivity Peripheral nervous system
Abbreviations
DN Diabetic peripheral neuropathy
DRG Dorsal root ganglia
GLO1 Glyoxalase I
RAGE Receptor for AGEs
SNP Single nucleotide polymorphism

\section{Introduction}

Diabetic peripheral neuropathy (DN) is a common secondary complication of long-standing hyperglycaemia as a consequence of diabetes mellitus [1]. Over $50 \%$ of diabetic patients suffer from DN with the prevalence increasing with duration of diabetes [2]. The majority of diabetic patients present with insensate neuropathy or negative symptoms, although estimates have varied widely, suggesting that 10 $50 \%$ of diabetic patients have painful neuropathy or positive symptoms [3-5]. However, a clear understanding of the underlying pathological mechanisms that determine which signs and symptoms of neuropathy, either positive or negative, arise in certain patients has yet to be determined.

One of the mechanisms linked to neuronal dysfunction in DN is the accumulation of AGEs [6,7]. Non-enzymatic 
glycation modifies lipids, nucleic acids, and both intra- and extra-cellular proteins, thereby altering normal cellular functions [8]. Signalling pathways activated through the receptor for AGEs (RAGE) also cause sensory neuron dysfunction, although uncertainty remains over the ligands that produce these effects $[9,10]$. In clinical studies and rodent models of diabetes, AGEs accumulate in sites affected by diabetic complications including the kidney, retina and peripheral nerves [11]. In diabetic patients, the accumulation of AGEs in the skin precedes clinical neuropathy [12], correlates with the severity of symptoms [12] and predicts the progression of DN [13].

Recently, reactive dicarbonyls or $\alpha$-oxoaldehydes such as methylglyoxal, glyoxal and 3-deoxyglucose have been found to be important precursors of AGEs and to contribute in their own right to diabetic complications [14, 15]. Reactive dicarbonyls are formed as a normal by-product of many metabolic pathways, including glycolysis, protein breakdown, lipid peroxidation and degradation of glycated proteins, all of which are enhanced in diabetes mellitus [7, 16]. $\alpha$-Oxoaldehydes are up to 20,000 -fold more reactive than glucose, leading to increased carbonyl stress and accelerated production of AGEs [17]. Importantly, $\alpha$ oxoaldehydes are elevated in diabetic patients [18]. Therefore, reactive dicarbonyls are thought to have an important role in the pathogenesis of $\mathrm{DN}$.

The glyoxalase enzyme system, composed of glyoxalase I (GLO1) and glyoxalase II, is a key cellular pathway that detoxifies reactive dicarbonyls and limits AGE formation. GLO1 levels and activity can be altered in disease states including diabetes [19-21]. Thus, GLO1 has been investigated in diabetic retinopathy, nephropathy, cardiomyopathy and endothelial dysfunction [22]. However, the distribution and functional role of GLO1 have not been investigated in $\mathrm{DN}$. The present study was designed to investigate the distribution and abundance of GLO1 in the peripheral nervous system and to better understand its potential role in modulating the development of DN.

\section{Methods}

Animals Male C57BL/6 (Charles River, Sulzfeld, Germany), A/J, BALB/cJ, 129P3/J, C3H/HeJ, and DBA/ 2J mice (Jackson, Bar Harbor, ME, USA) were purchased at 7 weeks of age, 1 week prior to beginning experiments. Mrgd (also known as Mrgprd) mice were generated by D. Anderson (Division of Biology, California Institute of Technology, Pasadena, CA, USA) and maintained as a breeding colony. Genotypes were confirmed as previously described [23]. The animals were housed in 12/12-h light/ dark cycle under pathogen free conditions. Mice had free access to standard rodent chow $(8,604,4 \%$ energy from fat;
Harlan Teklad, Madison, WI, USA) and water. All animal use was in accordance with NIH guidelines and conformed to principles specified by the University of Kansas Medical Center Animal Care and Use Protocol.

Streptozocin induction of diabetes Diabetes was induced in 8-week-old male $\mathrm{C} 57 \mathrm{BL} / 6$ and $\mathrm{A} / \mathrm{J}$ mice. C57BL/6 mice were injected with a single intraperitoneal injection of streptozocin $(180 \mathrm{mg} / \mathrm{kg}$ body weight; Sigma, St Louis, MO, USA) dissolved in $10 \mathrm{mmol} / \mathrm{l}$ sodium citrate buffer, $\mathrm{pH}$ 4.5. A/J mice were injected with $85 \mathrm{mg} / \mathrm{kg}$ streptozotocin followed by a second injection with $65 \mathrm{mg} / \mathrm{kg}$ streptozotocin $24 \mathrm{~h}$ later. Controls received sodium citrate buffer alone. Animals of either strain that failed to develop hyperglycaemia by 1 week after initial injection were reinjected with $85 \mathrm{mg} / \mathrm{kg}$ streptozotocin. Food was removed from all cages for $3 \mathrm{~h}$ before and after streptozotocin injection. Animals did not receive insulin at any time.

Glucose measurements Animal weight and blood glucose levels (glucose diagnostic reagents; Sigma) were measured 1 week after streptozotocin injection and every week thereafter. Mice were considered to have diabetes if their non-fasting blood glucose level, measured from tail vein sampling for intermediate measures and from decapitation pool for the terminal measure, was $>12.0 \mathrm{mmol} / \mathrm{l}$ at every measurement.

Behavioural testing Mechanical behavioural responses to a Semmes Weinstein-von Frey monofilament (1.0 or $1.4 \mathrm{~g})$ (Stoelting, Wood Dale, IL, USA) were assessed at 4, 5 and 6 weeks after streptozotocin injection. Mice underwent a training session on the day prior to the first day of testing. Mice were placed in individual clear plastic cages $(11 \times 5 \times$ $3.5 \mathrm{~cm}$ ) on a wire mesh screen elevated $55 \mathrm{~cm}$ above the table and allowed to acclimatise for $30 \mathrm{~min}$. The combined mean per cent withdrawal of three applications to each hindpaw was calculated for each animal for each testing session. The group means were calculated. Mice were killed following behavioural testing at 6 weeks post streptozotocin.

Immunohistochemistry Unfixed lumbar dorsal root ganglia (DRG), sciatic nerve and spinal cord were dissected, frozen, sectioned in $16-$ to $20-\mu \mathrm{m}$ cross-sectional serial sections, mounted on slides (Superfrost Plus; Fisher Scientific, Chicago, IL, USA) and stored at $-20^{\circ} \mathrm{C}$. After thawing for $5 \mathrm{~min}$ at room temperature, slide-mounted tissue was circled with a Pap Pen (Research Products International, Mt Prospect, IL, USA) to create a hydrophobic ring. Tissue sections were then covered with a blocking solution $(0.5 \%$ $\mathrm{wt} / \mathrm{vol}$. porcine gelatine, $1.5 \%$ vol./vol. normal donkey serum, $0.5 \%$ vol./vol. Triton-X, Superblock buffer; Pierce, 
Rockford, IL, USA) for $1 \mathrm{~h}$ at room temperature. Primary antibodies were incubated overnight at $4^{\circ} \mathrm{C}$. For GLO1 immunohistochemistry, a mouse anti-GLO1 primary antibody (1:100; Abcam, Cambridge, MA, USA) and a donkey anti-mouse secondary antibody (Alexa 488 or 555, 1:2,000; Molecular Probes, Eugene, OR, USA) were used to label positive cells in the L4/5/6 DRG, sciatic nerve and spinal cord. Primary rabbit anti-neurofilament H $(1: 2,500$; Chemicon, Billerica, MA, USA) or rabbit anti-peripherin (1:1,000; Chemicon) with donkey anti-rabbit secondary antibody (Alexa 555, 1:2,000; Molecular Probes) were used to label and counterstain cell populations in lumbar DRG. Sections were washed twice for 5 min with PBS with $0.01 \%$ vol./vol. Triton-X followed by incubation for $1 \mathrm{~h}$ with fluorochrome-conjugated secondary antibody diluted in PBS with $0.01 \%$ vol./vol. Triton-X and Superblock (Pierce). Following three washes with PBS, slides were coverslipped and stored at $4{ }^{\circ} \mathrm{C}$ until viewing. Staining was blocked by preadsorption of the mouse anti-GLO1 antibody with human GLO1 (R\&D Systems, Minneapolis, MN, USA).

Quantitative real-time PCR Total RNA was isolated from sciatic nerve, DRG and brain using Trizol reagent (Ambion, Austin, TX, USA) and a kit (RNeasy Mini; Qiagen, Valencia, CA, USA). The concentration and purity were determined using an analyser (2100; Agilent Technologies, Santa Clara, CA, USA). Total RNA $(0.63 \mu \mathrm{g})$ was synthesised directly into cDNA using a kit (iScript cDNA Synthesis Kit; Bio-Rad, Hercules, CA, USA). Quantitative RT-PCR was performed using a kit (iScript One-Step RTPCR kit with SYBR green; Bio-Rad). The primers are shown in the Electronic supplementary material (ESM) Table 1.

All reactions were performed in triplicate. $\Delta C_{t}$ values and fold changes were calculated using the Pfaffl analysis method [24]. The mRNA levels for Glo1 were normalised to Gapdh.

Western blot Brain, lumbar spinal cord, sciatic nerve and DRG were rapidly isolated, frozen in liquid nitrogen and stored at $-80^{\circ} \mathrm{C}$. Tissue was homogenised for $2 \mathrm{~min}$ in $50 \mu \mathrm{l}$ cell extraction buffer (Invitrogen, Carlsbad, CA, USA) with protease inhibitor cocktail (Sigma), $200 \mathrm{mmol} / 1 \mathrm{NaF}$ and $200 \mathrm{mmol} / 1 \mathrm{Na}_{3} \mathrm{VO}_{4}$. The homogenates were incubated on ice for $30 \mathrm{~min}$ before centrifugation for $10 \mathrm{~min}$ at $4,500 \times \mathrm{g}$ and $4{ }^{\circ} \mathrm{C}$. Protein concentrations were determined using a protein assay based on the Bradford assay (Bio-Rad, Sydney, NSW, Australia).

Samples containing $100 \mu \mathrm{g}$ of protein were separated by electrophoresis through $4 \%$ to $20 \%$ SDS-PAGE gels $\left(125 \mathrm{~V}, 1.5 \mathrm{~h}, 4^{\circ} \mathrm{C}\right)$ and transferred on to nitrocellulose paper $\left(35 \mathrm{~mA}\right.$, overnight, $\left.4^{\circ} \mathrm{C}\right)$. Nitrocellulose membranes were blocked with blocking buffer ( $3 \%$ non-fat milk and $0.05 \%$ vol./vol. Tween-20 in phosphate buffered saline) for $1 \mathrm{~h}$ at room temperature to block non-specific binding sites, followed by overnight incubation with a goat anti-GLO1 primary antibody (R\&D Systems) diluted $1: 5,000$ in blocking buffer at $4{ }^{\circ} \mathrm{C}$. The donkey anti-goat IgGhorseradish peroxidase secondary antibody (Santa Cruz, Santa Cruz, CA, USA) was used diluted $1: 2,500$ in blocking buffer at room temperature for $1 \mathrm{~h}$.

Nitrocellulose membranes were stripped using western blot stripping buffer (Restore Plus; Pierce), followed by $1 \mathrm{~h}$ incubation with an actin primary antibody (Millipore, Billerica, MA, USA) diluted 1:100,000 in blocking buffer at room temperature. The donkey anti-mouse IgGhorseradish peroxidase secondary antibody (Santa Cruz) was used diluted 1:2,500 in blocking buffer at room temperature for $1 \mathrm{~h}$. The chemiluminescent signal was acquired using Supersignal West Femto Maximum Sensitivity Substrate (Pierce) and a CCD camera (BioSpectrum Imaging System; UVP, Upland, CA, USA). NIH ImageJ software (http://rsbweb.nih.gov/ij/index.html, Nov. 2010) was used to measure and quantify densitometry readings.

Statistical analysis Data are expressed as mean \pm SEM. Number of animals per given experimental setting is given as $n$ value, unless otherwise indicated. Differences were analysed by two-tailed Student's $t$ test for unpaired data and repeated measures ANOVA followed by Bonferroni's test, as appropriate. Significance was defined as $p \leq 0.05$.

\section{Results}

Genetic differences in Glo1 mRNA expression Quantitative analysis of Glo1 expression in DRG revealed that mRNA expression varied in six different strains of inbred mice. $\mathrm{C} 57 \mathrm{BL} / 6, \mathrm{BALB} / \mathrm{cJ}$ and $129 \mathrm{P} 3 / \mathrm{J}$ mice showed the lowest mRNA expression with $\Delta \mathrm{C}_{\mathrm{t}}$ values of $2.828 \pm 0.205$ (mean \pm SEM), $2.578 \pm 0.095$ and $2.568 \pm 0.087$, respectively, while $\mathrm{C} 3 \mathrm{H} / \mathrm{HeJ}$ and $\mathrm{DBA} / 2 \mathrm{~J}$ had intermediate Glol mRNA expression with $\Delta \mathrm{C}_{\mathrm{t}}$ values of $1.753 \pm 0.093$ and $1.227 \pm$ 0.076 (Fig. 1a, b). With a $\Delta \mathrm{C}_{\mathrm{t}}$ value of $0.509 \pm 0.142, \mathrm{~A} / \mathrm{J}$ mice showed the highest levels of mRNA expression among the strains examined, with a fivefold increase over C57BL/6 (Fig. 1a, b). These results were also similar in the brain and sciatic nerve of A/J mice, with 6.7- and 4.2-fold higher levels of Glo1 mRNA than in C57BL/6 mice (data not shown).

Characterisation of GLO1 abundance in the nervous system GLO1 immunoreactivity was detected in the central and peripheral nervous systems (Fig. 2a). In the lumbar spinal cord of 8-week-old non-diabetic C57BL/6 mice, 
a
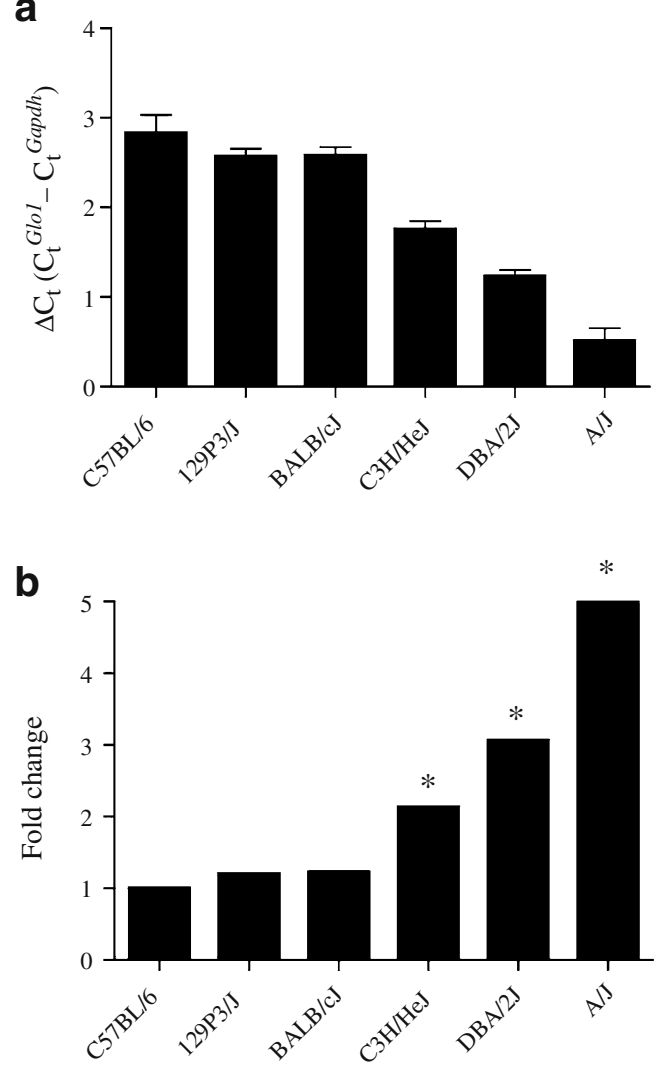

Fig. 1 a Comparison of Glo1 mRNA expression in the DRG from inbred strains of non-diabetic mice as labelled; $n=3$ for each strain. Expression was normalised to Gapdh. b Fold change in Glo1 mRNA expression relative to $\mathrm{C} 57 \mathrm{BL} / 6$ mice. ${ }^{*} p<0.05$ vs $\mathrm{C} 57 \mathrm{BL} / 6$

GLO1 localised to lamina I and II of the dorsal horn (Fig. 2b), interneurons (Fig. 2b), ependymal cells of the central canal (Fig. 2e) and ventral horn motor neurons (Fig. 2f). In the peripheral nervous system, approximately $36 \%$ of L4/L5/L6 DRG neurons $(1,984$ of 5,501$)$ produced GLO1 at very high levels; these neurons were predominantly small with areas ranging from 30 to $337 \mu \mathrm{m}^{2}$ and an average area of $120 \mu \mathrm{m}^{2}$ (Fig. 2c, g). Consistent with these findings, $\sim 96 \%(2,115$ of 2,198) of GLO1+ neurons produced peripherin (Fig. 3e-h), a marker of small diameter, unmyelinated neurons with areas ranging from 27 to $340 \mu \mathrm{m}^{2}$ and an average area of $148 \mu \mathrm{m}^{2}$. Accordingly, $<7 \%$ (138 of 1,994) of GLO1+ cells produced heavy chain neurofilament $\mathrm{H}$, which labels medium and large diameter, myelinated neurons with areas ranging from 126 to $1,260 \mu^{2}$ and an average area of $552 \mu \mathrm{m}^{2}$ (Fig. 3a-d). Correspondingly, GLO1 was produced in small diameter axons in the sciatic nerve (Fig. 2d). Moreover, GLO1 appears to be selective to small C-fibres, a finding based on the somal staining pattern in the DRG, the lack of co-localisation of GLO1 with neurofilament $\mathrm{H}$ large myelinated axons (Fig. 2h, Fig. 3c) and GLO1 colocalisation with peripherin-positive axons (Fig. 3g, h).
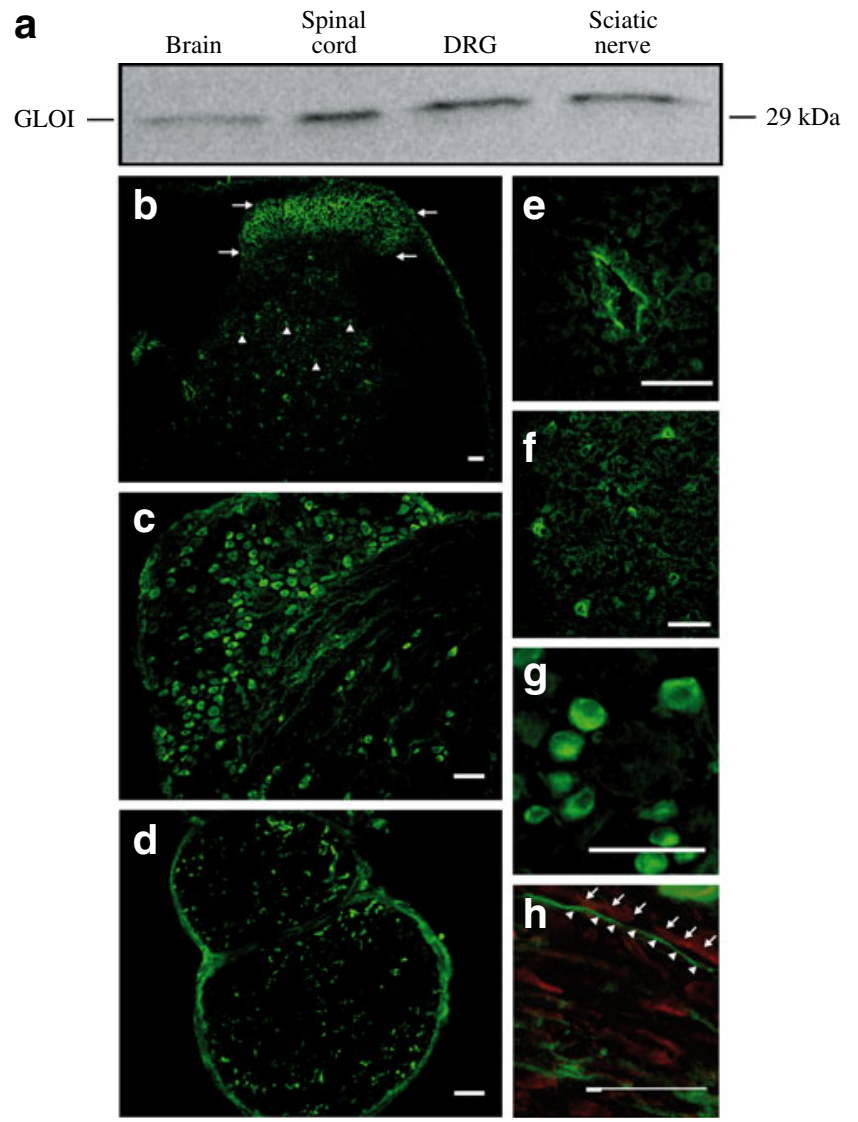

Fig. 2 GLO1 abundance in the nervous system. a Representative western blot showing abundance of GLO1 in tissue, as indicated, of non-diabetic C57BL/6 mice; $n=3$. Immunofluorescence staining of the lumbar spinal cord (b), lumbar DRG (c), and sciatic nerve (d), showing GLO1 abundance and localisation. In $\mathbf{b}$, arrowheads indicate GLO1-positive interneurons; arrows indicate GLO1-positive terminals in the superficial lamina. Enhanced views of GLO1-positive ependymal cells of the central canal (e), anterior horn cells (f), neurons of the DRG (g) and axons of the sciatic nerve in longitudinal section, counterstained with neurofilament $\mathrm{H}$ (red) (h). In $\mathbf{h}$, arrowheads indicate a GLO1-positive axon; arrows indicate a neurofilament $\mathrm{H}$ positive axon. Scale bars, $50 \mu \mathrm{m}$

Mrgd mice have previously been reported to express green fluorescent protein (eGFP) from the Mas-related G proteincoupled receptor D locus, which is expressed exclusively in non-peptidergic DRG neurons innervating the epidermis [25]. Because GLO1+ neurons were predominantly small, unmyelinated neurons, $\mathrm{Mrgd}$ mice were used to determine whether GLO1 was expressed by peptidergic or nonpeptidergic sensory neurons. Only 8\% (93 of 1,072) of Mrgd GFP+ neurons produced GLO1, suggesting that GLO1 is predominantly produced by peptidergic sensory neurons in L4/L5/L6 DRG (Fig. 4).

Streptozotocin-induced diabetes Following streptozotocin injection, C57BL/6 and A/J mice developed significantly higher blood glucose, which persisted throughout the 6-week 

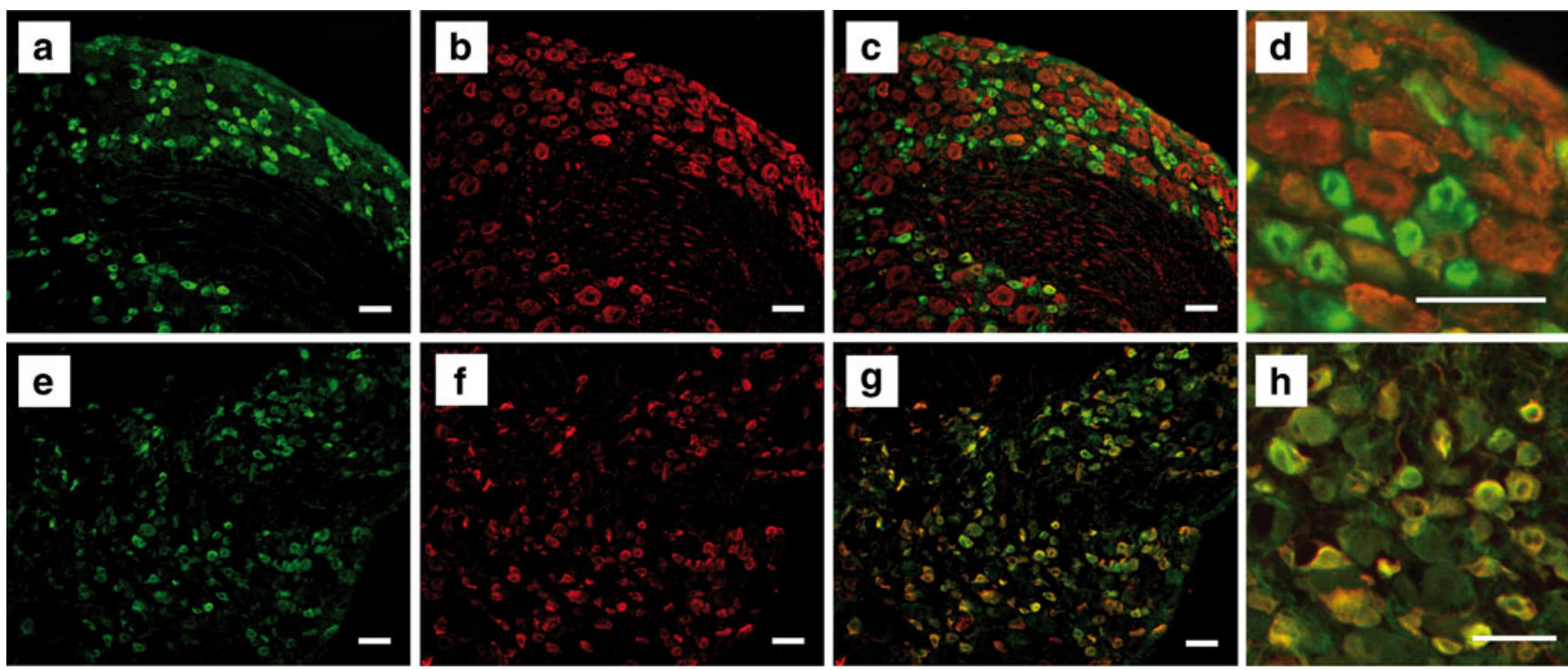

Fig. 3 GLO1 abundance in lumbar DRG sensory neurons. Immunofluorescence staining for GLO1 (a, e) with counterstaining for neurofilament $\mathrm{H}(\mathbf{b})$ and peripherin (f). Merged images $(\mathbf{c}, \mathbf{g})$ show that GLO1 is localised to small neurons in the DRG; $n=3$. d, $\mathbf{h}$ Enhanced views of the merged images in $\mathbf{c}, \mathbf{g}$. Scale bars, $50 \mu \mathrm{m}$

$(1.0 \mathrm{~g})$ was chosen to test the mechanical sensitivity of $\mathrm{A} / \mathrm{J}$ mice with a view to detecting behavioural changes after diabetes induction.

Mechanical sensitivity of the hindpaw was tested at 4, 5 and 6 weeks after streptozotocin injection. Consistent with this strain and model, diabetic C57BL/6 mice showed reduced responses to a $1.4 \mathrm{~g}$ von Frey monofilament (Fig. 6c) [23, 26]. After 4 weeks of diabetes, diabetic C57BL/6 mice displayed a withdrawal response to mechanical stimulation of $41.2 \pm 5.32 \%$ (mean \pm SEM), while non-diabetic mice responded $64.4 \pm 11.7 \%$ of the time. This mechanical insensitivity persisted and worsened with progression of the disease, with diabetic mice withdrawing $23.2 \pm 2.97 \%$ at 6 weeks post streptozotocin (Fig. $6 \mathrm{c}$ ).

Conversely, as early as 1 week following streptozotocin injection, diabetic $\mathrm{A} / \mathrm{J}$ mice displayed increased responses to a $1 \mathrm{~g}$ von Frey monofilament (data not shown). Mechanical allodynia was present at 4, 5 and 6 weeks following streptozotocin injection, with diabetic $\mathrm{A} / \mathrm{J}$ mice responding nearly $75 \%$ of the time (Fig. $6 \mathrm{~b}$ ). Thus, diabetic
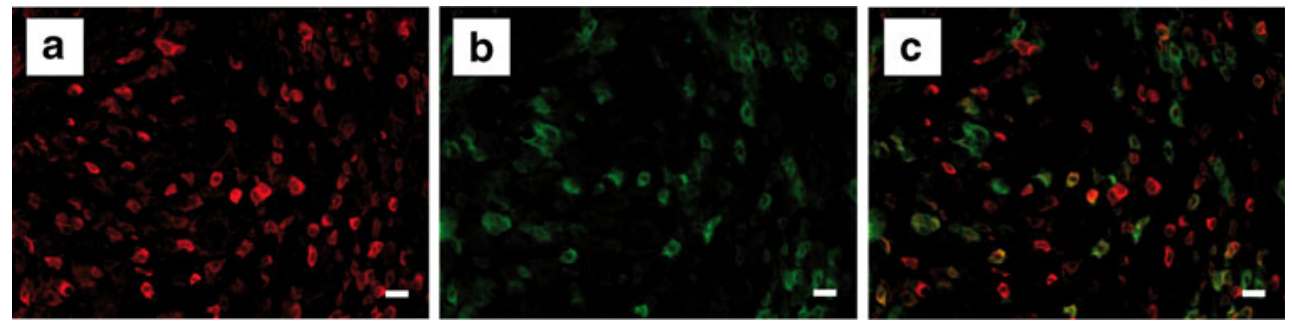

Fig. 4 GLO1 abundance in peptidergic C-fibre sensory neurons in the DRG. Immunofluorescence staining for GLO1 in the lumbar DRG of Mrgd mice (a), which produce GFP from the Mrgd locus in non- peptidergic neurons (b); $n=3$. c Merged image showing GLO1 abundance primarily in peptidergic C-fibres. Scale bars, $50 \mu \mathrm{m}$ 
Fig. 5 Blood glucose (a) and body weight (b) of C57BL/6 ( $n=5$ non-diabetic, black circles; $n=9$ diabetic, white circles) and A/J ( $n=5$ non-diabetic, black triangles; $n=9$ diabetic, white triangles) mice. Data represent means $\pm \mathrm{SEM} ; * * * p<0.001$ and $* * * * p<0.0001$ vs $\mathrm{A} / \mathrm{J}$ nondiabetic; ${ }^{\dagger} p<0.05,{ }^{\dagger \dagger} p<0.001$ and ${ }^{\dagger \dagger \dagger} p<0.0001$ vs C57BL/6 non-diabetic

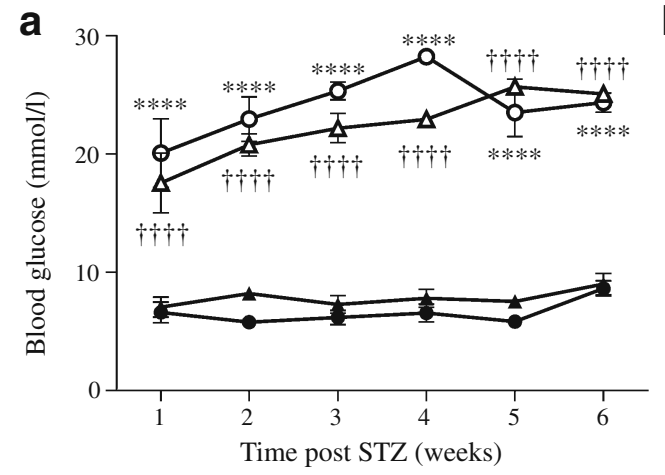

C57BL/6 mice developed increased mechanical thresholds and severe mechanical insensitivity, whereas diabetic A/J mice developed reduced mechanical thresholds and mechanical allodynia after 4 weeks of diabetes.

GLO1 distribution and abundance in diabetes After 6 weeks of diabetes, GLO1 protein levels in the DRG of diabetic $\mathrm{A} / \mathrm{J}$ mice remained similar to those in non-diabetic mice (Fig. 7a, b). In contrast, diabetic C57BL/6 mice showed a $59.6 \%$ reduction of GLO1 abundance in the lumbar DRG (Fig. 7a, c). There was no difference in Glo1 mRNA in diabetic C57BL/6 mice compared with nondiabetic counterparts (Fig. 7d).

GLO1 distribution in the DRG did not change following diabetes induction. Small-diameter neurons predominantly produced GLO1 in non-diabetic and diabetic mice (Fig. 8a-d). The percentage of GLO1+ neurons from both diabetic strains was similar to that of their non-diabetic counterparts $(30 \pm 2 \%$ [mean $\pm \mathrm{SEM}]$ for non-diabetic C57BL/6, $n=663$ of 2,194 , vs $28 \pm 2 \%$ for diabetic C57BL/ $6, n=756$ of 2,660 ; and $29 \pm 2 \%$ for non-diabetic A/J, $n=597$ of 2,032 , vs $26 \pm 1 \%$ for diabetic A/J, $n=468$ of 1,795 ) (Fig. 8e). Similarly, the number of GLO1+ neurons from diabetic $\mathrm{C} 57 \mathrm{BL} / 5$ and $\mathrm{A} / \mathrm{J}$ mice was comparable (Fig. 8e).

\section{Discussion}

Chronic hyperglycaemia is the main driving force of the development and progression of DN. Elevated intra- and extracellular glucose concentrations lead to accelerated production of AGEs. AGEs alter the function of many proteins, including tubulin, mitochondrial electron transport chain proteins, insulin and neuronal extracellular matrix proteins $[8,27-31]$. AGEs are elevated in peripheral nerves and skin of diabetic patients and rodents [11, 12, 32, 33]; indeed, elevated levels have also been measured in plasma of type 1 diabetic patients without complications, suggesting AGEs may have a role in the development and/or progression of diabetic neuropathy [34]. GLO1, a key enzyme in anti-glycation defence, is critical to preventing this accumulation of AGEs and limiting their toxic effects by breaking down the highly reactive precursors, $\alpha$ oxoaldehydes.

Here, Glol mRNA expression in the DRG varied significantly in multiple inbred strains of mice. A previous study using Affymetrix exon arrays also reported high genetic variability of Glo1 in the amygdala of a large panel of inbred strains of mice [35]. Williams et al. discovered that the genomic region encoding Glo1 exists as copy
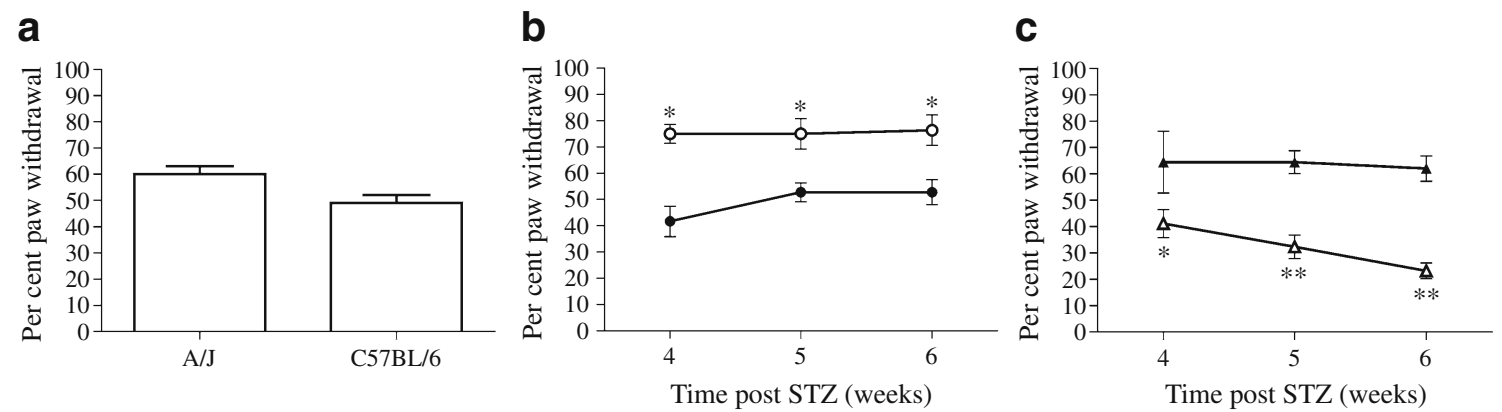

Fig. 6 Behavioural responses of mice to mechanical stimulation of the hind paw. a Baseline behavioural measurements of non-diabetic $\mathrm{A} / \mathrm{J}(n=15)$ and $\mathrm{C} 57 \mathrm{BL} / 6(n=12)$ mice using a $1.4 \mathrm{~g}$ monofilament. Per cent paw withdrawal is the percentage of responses following six repeated applications of von Frey monofilaments. A $1.0 \mathrm{~g}$ or $1.4 \mathrm{~g}$ monofilament was applied to the hindpaws of $\mathrm{A} / \mathrm{J}$ (b) $(n=4$ nondiabetic, black circles; $n=4$ diabetic, white circles) and C57BL/6 (c) ( $n=7$ non-diabetic, black triangles; $n=34$ diabetic, white triangles) mice, respectively. Data represents means \pm SEM; $* p<0.05$ and ${ }^{* *} p<0.01$ vs non-diabetic 
a

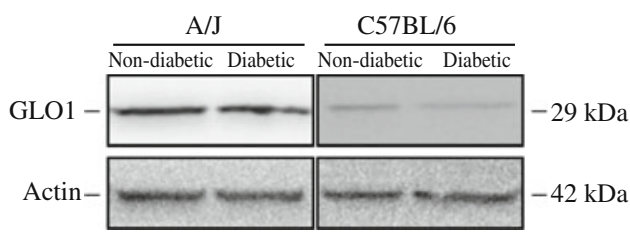

b

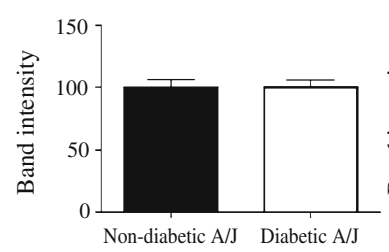

C

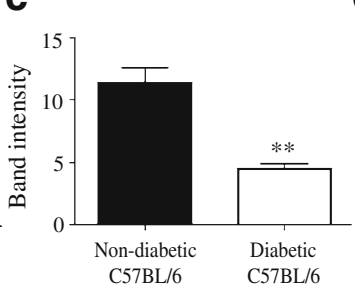

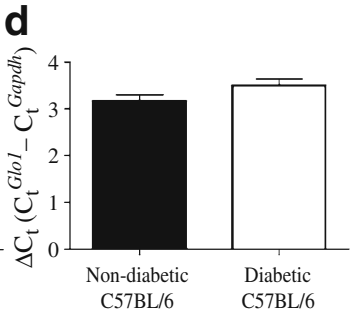

Fig. 7 Effect of diabetes on levels of GLO1 in the DRG of A/J and $\mathrm{C} 57 \mathrm{BL} / 6$ mice. a Representative western blots from $\mathrm{A} / \mathrm{J}$ and C57BL/6 mice, as labelled, for GLO1 and actin. Quantification of protein band intensities for $\mathrm{A} / \mathrm{J}$ mice ( $n=3$ per group) (b) and
C57BL/6 mice ( $n=3$ per group) (c). Band intensities are shown as normalised means \pm SEM. d Comparison of Glo1 mRNA expression in the DRG from mice as labelled after 6 weeks of diabetes; $n=3$. $* * p<0.01$ vs non-diabetic number variant in mice, with certain strains undergoing duplications and others having lost the duplicated region, which could explain expression differences in the DRG [35]. Interestingly, copy number variants have recently been characterised in humans as a substantial source of genetic
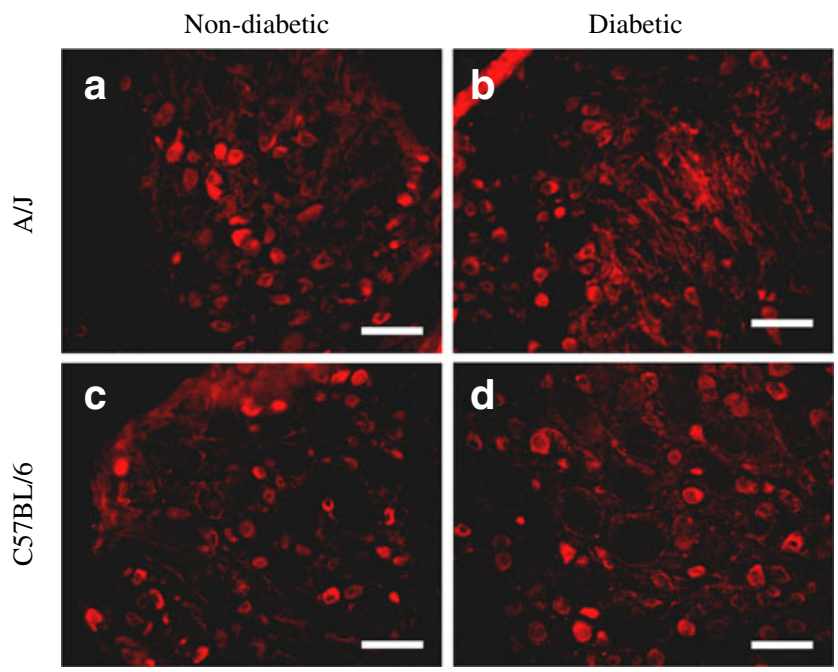

e

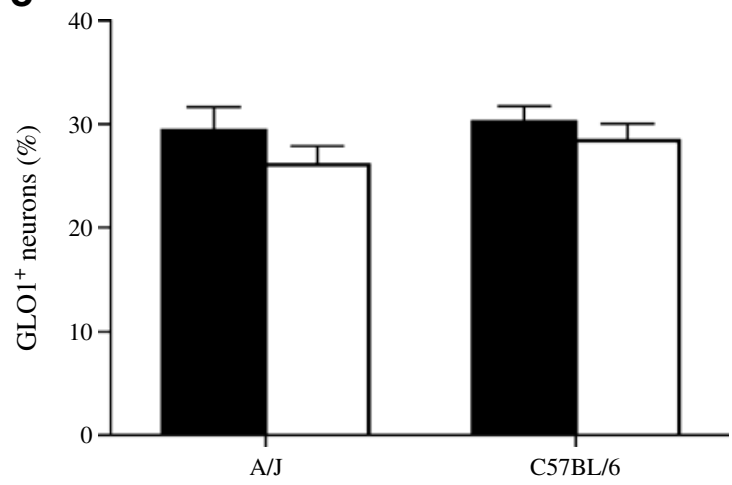

Fig. 8 Pattern of GLO1 abundance in the DRG after 6 weeks of diabetes. Immunofluorescence staining for GLO1 in the DRG of (a) $\mathrm{A} / \mathrm{J}$ non-diabetic $(n=3)$ and (b) diabetic $(n=3)$, and (c) C57BL/6 nondiabetic $(n=3)$ and (d) diabetic $(n=3)$ mice. Scale bars, $50 \mu \mathrm{m}$. e Quantification of GLO1-positive neurons as percentage of total neurons in the DRG. Data represent means \pm SEM. Black bars, nondiabetic mice; white bars, diabetic mice diversity and disease [36, 37]. While amplification of Glo1 has been described in human cancers, natural variation of a copy number variant encompassing Glol has yet to be described in humans [38]. However, many intronic and exonic single nucleotide polymorphisms (SNPs) and SNPs located in regulatory $3^{\prime}$ and $5^{\prime}$ untranslated regions have been described [39]. This suggests that underlying genetic differences, alterations in regulation or modifications in disease may influence the expression and activity of GLO1 $[8,40]$. To date, little has been done to define these in humans.

The present study is the first to characterise expression of Glol in the peripheral nervous system. Our results reveal that expression of Glol is restricted to small, unmyelinated peptidergic neurons in the DRG, which are primarily responsible for transmission of noxious or painful sensory information. This was particularly interesting given the critical function, highly conserved nature and previous reports on the ubiquitous presence of GLO1 [41]. Generally, this suggests that populations of neurons may be vulnerable to different types of damage in diabetes. Specifically, non-peptidergic C-fibres and myelinated neurons may experience increased carbonyl stress and accumulation of AGEs, leading to altered neuronal function. Alternatively, peptidergic neurons may be more protected from the toxic effects of elevated glucose and reactive dicarbonyls due to the abundance of GLO1. This may have significant consequences on the phenotype of altered sensation in DN.

In this study, responses to mechanical stimuli in diabetic mice with different levels of GLO1 varied. Previous studies have also suggested a link between mechanical and thermal sensation, GLO1 and AGEs. Toth et al. and Bierhaus et al. showed that RAGE has a role in sensory neuron dysfunction in diabetes [9, 42]. Diabetic Rage (also known as Ager $)^{-/}$mice were protected from pathological, physiological and behavioural signs of DN [6, 9, 42]. Mechanical sensitivity is mediated by unmyelinated and myelinated sensory neurons, which respond to a range of sensory stimulus modalities. Indeed, most $\mathrm{C}$-fibres also respond to 
mechanical sensitivity [43]. Thus, afferent information encoding mechanical information probably converges in the spinal cord to convey complex mechano-sensory information. It is therefore plausible to suggest that a balance between fibre types is required to convey appropriate sensory information from the periphery. The ability of specific neuronal populations to be more susceptible to and/or protect against the hyperglycaemia-induced damage that occurs in diabetes may alter this balance, leading to abnormal peripheral nociceptive input and producing different signs and symptoms of neuropathy.

Although the present study does not directly address the mechanisms causing positive or negative mechanical sensitivity associated with DN, this issue is clearly important and relevant to humans with DN. Sensory loss, including chronic numbness and insensitivity to pain or touch, develops in the majority of affected human patients. Painful symptoms, including tactile allodynia, are reported in approximately $30 \%$ of patients with $\mathrm{DN}$ and are often present early in disease progression, the prevalence being slightly higher in type 2 diabetes [44, 45]. This dichotomy in positive vs negative symptoms is reflected in animal models of DN, with some resembling the painful and others the painless aspects of DN $[5,26,46]$. Our current findings in $\mathrm{C} 57 \mathrm{BL} / 6$ and $\mathrm{A} / \mathrm{J}$ mice are consistent with this feature and may point to ways of addressing how genetic differences, including altered GLO1 expression, help shape the phenotype of DN in diabetic patients.

Based on our findings, we hypothesise that an imbalance of fibre type input may underlie the development of positive or negative mechanical sensitivity. In the setting of high GLO1 abundance, as in A/J mice, peptidergic neurons may be protected from extensive damage by reactive dicarbonyls and retain the ability to transmit noxious sensory information. However, A-fibre and nonpeptidergic sensory neurons have no detectable production of GLO1 and may be more vulnerable to direct damage by reactive dicarbonyl, which leads to neuronal dysfunction in these fibres. This is supported by studies suggesting that a range of sensory afferents are likely to contribute to overall pain sensation, including A- and C-fibres [47]. Therefore, despite protection from GLO1, it is possible that peptidergic $\mathrm{C}$-fibre function may be affected by damage to other fibres. Conversely, in the setting of low GLO1 abundance, as in $\mathrm{C} 57 \mathrm{BL} / 6$ mice, peptidergic neurons may accumulate reactive dicarbonyl-derived AGEs and experience physiological dysfunction similar to that in other fibres. Thus, peptidergic $\mathrm{C}$-fibre mechano-thresholds may be increased due to intrinsic dysfunction stemming from reduced GLO1 levels and accumulation of reactive dicarbonyls.

Finally, our results revealed that GLO1 levels are reduced by diabetes in $\mathrm{C} 57 \mathrm{BL} / 6$ mice, which could also play a role in determining the phenotype of DN. Reductions in GLO1 in diabetic C57BL/6 mice could occur through increased proteosomal degradation, particularly if GLO1 itself is modified by methylglyoxal, or also by RAGEmediated reduction of GLO1 [8]. Both in vivo and in vitro overproduction of GLO1 has been shown to dramatically reduce levels of reactive dicarbonyls and AGEs [48-50]. However, it remains to be seen whether physiological overproduction is robust enough to produce similar reductions. Given the restricted distribution of GLO1 in the DRG and behavioural differences following induction of diabetes, our findings suggest that genetic variation in Glol could modify the spectrum of DN symptoms.

In conclusion, we have shown that GLO1 is predominantly produced in peptidergic sensory neurons in the DRG and that its abundance varies in two inbred strains of mice that display different mechanical sensitivity, suggesting each develops a different phenotype of neuropathy. These findings warrant further investigation into the role of GLO1 in DN.

Acknowledgements This work was supported by the Juvenile Diabetes Research Foundation and NIH RO1NS43314 to D.E. Wright, and by the Kansas IDDRC, P30 NICHD HD 002528.

M.M.J., J.M.R. and D.E.W. all contributed to the conception and design, analysis and interpretation, writing, and final approval of the published version.

Duality of interest The authors declare that there is no duality of interested associated with this manuscript.

\section{References}

1. Figueroa-Romero C, Sadidi M, Feldman EL (2008) Mechanisms of disease: the oxidative stress theory of diabetic neuropathy. Rev Endocr Metab Disord 9:301-314

2. Zochodne DW, Ramji N, Toth C (2008) Neuronal targeting in diabetes mellitus: a story of sensory neurons and motor neurons. Neuroscientist 14:311-318

3. Veves A, Backonja M, Malik RA (2008) Painful diabetic neuropathy: epidemiology, natural history, early diagnosis, and treatment options. Pain Med 9:660-674

4. Tavakoli M, Malik RA (2008) Management of painful diabetic neuropathy. Expert Opin Pharmacother 9:2969-2978

5. Calcutt NA, Backonja MM (2007) Pathogenesis of pain in peripheral diabetic neuropathy. Curr Diab Rep 7:429-434

6. Toth C, Martinez J, Zochodne DW (2007) RAGE, diabetes, and the nervous system. Curr Mol Med 7:766-776

7. Ahmed N, Thornalley PJ (2007) Advanced glycation endproducts: what is their relevance to diabetic complications? Diab Obes Metab 9:233-245

8. Thornalley PJ (2008) Protein and nucleotide damage by glyoxal and methylglyoxal in physiological systems - role in ageing and disease. Drug Metabol Drug Interact 23:125-150

9. Toth C, Rong LL, Yang C et al (2008) Receptor for advanced glycation end products (RAGEs) and experimental diabetic neuropathy. Diabetes 57:1002-1017

10. Vincent AM, Perrone L, Sullivan KA et al (2007) Receptor for advanced glycation end products activation injures primary sensory neurons via oxidative stress. Endocrinology 148:548-558 
11. Karachalias N, Babaei-Jadidi R, Ahmed N, Thornalley PJ (2003) Accumulation of fructosyl-lysine and advanced glycation end products in the kidney, retina and peripheral nerve of streptozotocininduced diabetic rats. Biochem Soc Trans 31:1423-1425

12. Meerwaldt R, Links TP, Graaff $R$ et al (2005) Increased accumulation of skin advanced glycation end-products precedes and correlates with clinical manifestation of diabetic neuropathy. Diabetologia 48:1637-1644

13. Genuth S, Sun W, Cleary P et al (2005) Glycation and carboxymethyllysine levels in skin collagen predict the risk of future 10-year progression of diabetic retinopathy and nephropathy in the diabetes control and complications trial and epidemiology of diabetes interventions and complications participants with type 1 diabetes. Diabetes 54:3103-3111

14. de Arriba SG, Stuchbury G, Yarin J, Burnell J, Loske C, Munch G (2007) Methylglyoxal impairs glucose metabolism and leads to energy depletion in neuronal cells-protection by carbonyl scavengers. Neurobiol Aging 28:1044-1050

15. Ulrich P, Cerami A (2001) Protein glycation, diabetes, and aging. Recent Prog Horm Res 56:1-21

16. Thornalley PJ (2002) Glycation in diabetic neuropathy: characteristics, consequences, causes, and therapeutic options. Int Rev Neurobiol 50:37-57

17. Turk Z (2010) Glycotoxines, carbonyl stress and relevance to diabetes and its complications. Physiol Res 59:147-156

18. Nemet I, Turk Z, Duvnjak L, Car N, Varga-Defterdarovic L (2005) Humoral methylglyoxal level reflects glycemic fluctuation. Clin Biochem 38:379-383

19. Phillips SA, Mirrlees D, Thornalley PJ (1993) Modification of the glyoxalase system in streptozotocin-induced diabetic rats. Effect of the aldose reductase inhibitor Statil. Biochem Pharmacol 46:805-811

20. Miller AG, Smith DG, Bhat M, Nagaraj RH (2006) Glyoxalase I is critical for human retinal capillary pericyte survival under hyperglycemic conditions. J Biol Chem 281:11864-11871

21. Fujimoto M, Uchida S, Watanuki $T$ et al (2008) Reduced expression of glyoxalase-1 mRNA in mood disorder patients. Neurosci Lett 438:196-199

22. Ahmed N (2005) Advanced glycation endproducts-role in pathology of diabetic complications. Diab Res Clin Pract 67:3-21

23. Johnson MS, Ryals JM, Wright DE (2008) Early loss of peptidergic intraepidermal nerve fibers in an STZ-induced mouse model of insensate diabetic neuropathy. Pain 140:35-47

24. Pfaffl MW, Horgan GW, Dempfle L (2002) Relative expression software tool (REST) for group-wise comparison and statistical analysis of relative expression results in real-time PCR. Nucleic Acids Res 30:e36

25. Zylka MJ, Rice FL, Anderson DJ (2005) Topographically distinct epidermal nociceptive circuits revealed by axonal tracers targeted to Mrgprd. Neuron 45:17-25

26. Christianson JA, Ryals JM, McCarson KE, Wright DE (2003) Beneficial actions of neurotrophin treatment on diabetes-induced hypoalgesia in mice. J Pain 4:493-504

27. Williams SK, Howarth NL, Devenny JJ, Bitensky MW (1982) Structural and functional consequences of increased tubulin glycosylation in diabetes mellitus. Proc Natl Acad Sci USA 79:6546-6550

28. Rabbani N, Thornalley PJ (2008) Dicarbonyls linked to damage in the powerhouse: glycation of mitochondrial proteins and oxidative stress. Biochem Soc Trans 36:1045-1050

29. Schalkwijk CG, Brouwers O, Stehouwer CD (2008) Modulation of insulin action by advanced glycation endproducts: a new player in the field. Horm Metab Res 40:614-619

30. Duran-Jimenez B, Dobler D, Moffatt S et al (2009) Advanced glycation end products in extracellular matrix proteins contribute to the failure of sensory nerve regeneration in diabetes. Diabetes 58:2893-2903
31. Mendez JD, Xie J, Aguilar-Hernandez M, Mendez-Valenzuela V (2010) Molecular susceptibility to glycation and its implication in diabetes mellitus and related diseases. Mol Cell Biochem 344:185-193

32. Yu Y, Thorpe SR, Jenkins AJ et al (2006) Advanced glycation end-products and methionine sulphoxide in skin collagen of patients with type 1 diabetes. Diabetologia 49:2488-2498

33. Chabroux S, Canoui-Poitrine F, Reffet $S$ et al (2010) Advanced glycation end products assessed by skin autofluorescence in type 1 diabetics are associated with nephropathy, but not retinopathy. Diab Metab 36:152-157

34. Han Y, Randell E, Vasdev S et al (2009) Plasma advanced glycation endproduct, methylglyoxal-derived hydroimidazolone is elevated in young, complication-free patients with type 1 diabetes. Clin Biochem 42:562-569

35. Rt W, Lim JE, Harr B et al (2009) A common and unstable copy number variant is associated with differences in Glo1 expression and anxiety-like behavior. PLoS ONE 4:e4649

36. Perry GH, Yang F, Marques-Bonet T et al (2008) Copy number variation and evolution in humans and chimpanzees. Genome Res 18:1698-1710

37. Choy KW, Setlur SR, Lee C, Lau TK (2010) The impact of human copy number variation on a new era of genetic testing. BJOG 117:391-398

38. Santarius T, Bignell GR, Greenman CD et al (2010) GLO1-A novel amplified gene in human cancer. Genes Chromosom Cancer 49:711-725

39. Engelen L, Ferreira I, Brouwers O et al (2009) Polymorphisms in glyoxalase 1 gene are not associated with vascular complications: the Hoorn and CoDAM studies. J Hypertens 27:1399-1403

40. Ranganathan S, Ciaccio PJ, Walsh ES, Tew KD (1999) Genomic sequence of human glyoxalase-I: analysis of promoter activity and its regulation. Gene 240:149-155

41. Thornalley PJ (2003) Glyoxalase I-structure, function and a critical role in the enzymatic defence against glycation. Biochem Soc Trans 31:1343-1348

42. Bierhaus A, Haslbeck KM, Humpert PM et al (2004) Loss of pain perception in diabetes is dependent on a receptor of the immunoglobulin superfamily. J Clin Invest 114:1741-1751

43. Rau KK, McIlwrath SL, Wang H et al (2009) Mrgprd enhances excitability in specific populations of cutaneous murine polymodal nociceptors. J Neurosci 29:8612-8619

44. Sorensen L, Molyneaux L, Yue DK (2002) Insensate vs painful diabetic neuropathy: the effects of height, gender, ethnicity and glycaemic control. Diab Res Clin Pract 57:45-51

45. Quattrini C, Tesfaye S (2003) Understanding the impact of painful diabetic neuropathy. Diab Metab Res Rev 19(Suppl 1):S2-S8

46. Walwyn WM, Matsuka Y, Arai D et al (2006) HSV-1-mediated NGF delivery delays nociceptive deficits in a genetic model of diabetic neuropathy. Exp Neurol 198:260-270

47. Shields SD, Cavanaugh DJ, Lee H, Anderson DJ, Basbaum AI (2010) Pain behavior in the formalin test persists after ablation of the great majority of C-fiber nociceptors. Pain 151:422-429

48. Shinohara M, Thornalley PJ, Giardino I et al (1998) Overexpression of glyoxalase-I in bovine endothelial cells inhibits intracellular advanced glycation endproduct formation and prevents hyperglycemia-induced increases in macromolecular endocytosis. J Clin Invest 101:1142-1147

49. Morcos M, Du X, Pfisterer F et al (2008) Glyoxalase-1 prevents mitochondrial protein modification and enhances lifespan in Caenorhabditis elegans. Aging Cell 7:260-269

50. Ahmed U, Dobler D, Larkin SJ, Rabbani N, Thornalley PJ (2008) Reversal of hyperglycemia-induced angiogenesis deficit of human endothelial cells by overexpression of glyoxalase 1 in vitro. Ann NY Acad Sci 1126:262-264 